\title{
Health Literacy in the United States of America: Cost Perspectives
}

\author{
Emily Reeves, Alistair Fyfe, Alexis Bain \\ Midwestern State University, USA
}

\begin{abstract}
Health literacy in the United States of America is approached from multiple cost perspectives. The current effects of health literacy are not new to the medical world, however, as the need for medical attention has increased, the average literary level of the individual is decreasing. This has produced an indirectly proportional relationship between people that are not well versed in health care information and their use of health care facilities. There has been a demand for consumers to be more health literate individuals which would assist in removing the strain that the medical industry has been exposed to over the last few decades. Health literacy is a currency that is used to produce proper exchanges between patients, medical professionals, and healthcare facilities. As the medical industry continues to evolve and revolutionize, it has had its share of damning yields, due to the lack of understanding obtained by their consumers.
\end{abstract}

\section{Introduction}

Health literacy is the bridge between patients and medical facilities that fosters a conducive environment for effective disease prognosis and efficient treatment [37]. Complete healing through treatment is one of the avenues taken to enhance quality of life and to provide longer life expectancy. This has become a major challenge faced by many of the medical institutions in the United States, even though the United States has numerous physicians (specialists) and medical professionals, the number of people battling ailments is increasing exponentially [1], [2]. This increase can be attributed to the level of literacy that a patient has. This type of literacy is inclusive of a patient's understanding of healthcare information and their ability to obtain access to gain a full understanding and proper implementation of what they have been given [17]. Health literacy is a very vital tool for both medical organizations and consumers. It is defined by the Patient and Affordable Care Act of 2010, Title V (Association of University Centers on Disabilities, 2010; National Institute of Health, n.d.) as the level in which individuals have the ability to receive, process, and comprehend basic health information; while also having the capacity to identify services that are needed for appropriate healthcare regime.
Health literacy is a pivotal tool that initiates the healing process needed to overcome any ailment that patients are facing [27]. It can be depicted as the bonding agent between both patient and medical personnel. The depth and effectiveness of health literacy is dependent upon the patient's literary attributions [23]. The literary level of a patient is dependent upon their education levels however, this is not the sole contributor to a patient's ignorance [30]. Murnane et al. identified that higher level literacy is an individual's ability to do more than the just consume information but to reproduce this information in a way that emulates what was given to them [31]. In the healthcare industry, the duty of distributing pertinent information is solely dependent upon healthcare professionals, public health administration, epidemiologist, etc. [12].

In 1999 a study was conducted by the Ad Hoc Committee on health literacy. This study revealed that patients who require major healthcare attention, tend to lack the basic ability to read and comprehend necessary information which would allow them function successfully as patients. The $\mathrm{Ad} \mathrm{Hoc}$ Committee (1999) proposed that professionals and the public at large should be made aware of the issue at hand. One recommendation is that health literacy should be taught and emphasized through the education of medical students and physicians (Ad Hoc, 1999). This will yield an improvement in the patient-physician relationship and render fluent and smooth communication skills among both providers and patients.

The study that was conducted in 1999 by Ad Hoc is still a prevalent depiction of current day medical issues. In as recent as 2019 there is still a substantial number of individuals that suffer from literacy issues. Health illiteracy creates major disparities in the medical treatment plans of patients [26]. In an article written by LeDoux and Mann [25], it stated that approximately 80 million Americans suffer from literacy issues which renders them unable to adequately follow the demands of their healthcare regimen. This article proved that health literacy is still a significant issue in the United States [26]. In 30 years, the healthcare industry has faced a lot of changes, but the effects of healthcare illiteracy still remain. Health literacy is an issue must be combatted to preserve quality of life and to increase life expectancy rate. 
America is a country that continuously revolutionizes medical instrumentation and practices, however, their life expectancy rates are low in comparison to Canada, Great Britain and Germany [43]. Healthcare literacy can be associated as a problem in healthcare outcomes. It can be contributed to low medical accessibility and higher healthcare needs (demands) [41]. Billions of dollars are pumped into the American medical industry, however, their yield of satisfactory results is unfavorable [1].

\section{Health Literacy as Currency}

Health literacy is perceived as a navigational tool that is used to explore, determine, and understand the educational materials that would be useful in assisting a patient in making appropriate health decisions [36]. It is critical to speak to patients in a way that they can understand. Unfortunately, if a patient is unable to understand simple and primary level information, then basic healthcare information would render them completely incompetent. Therefore, if patients cannot fully comprehend basic medical information about their medical diagnosis and prognosis, they will not be able to fully comply with their treatment demands [29]. Miller [29] concluded that with increased health literacy, there was an increase in health adherence which acknowledges that health literacy must be provided to patients. According to the World Health Organization (WHO) (2010), "Health literacy represents the cognitive and social skills which determine the motivation and ability of individuals to gain access to, understand and use information in ways which promote and maintain good health and follow instructions for treatment," [44]. For patients, this can range from a person's ability to calculate cholesterol levels to choosing which insurance or health plan to enrollment into.

\section{Health Literacy and Poverty}

Childress et al. [8] reported that the effects of poverty are cyclical in nature which places a significant strain on people that are living at poverty levels. One factor that was recognized by Childress et al. was that the lack of education affects healthcare needs, as well as the lack of education, can also be affected by healthcare needs. This shows that healthcare and education are synonymous of each other and that if one is lacking the other will not function efficiently. The findings by Childress et al. [8] were reported in Haiti, which is considered a third world country. Unfortunately, some of their reports are very prevalent in the first world or developed countries. In developed countries it has been found that approximately 100 million people are functionally illiterate (OECD, 1997). Lattier emphasized that of the 100 million people approximately 32 million American adults are functionally illiterate. Functional illiterate people are people who can engage in activities that require very basic or minimal use of literacy tools [24]. Meaning that they can read, write, and comprehend at low levels, but they are not social inapt to adapt to more complex demands or societal needs [24]. The correlation between health and education has been a great interest for many researchers [34].

According to van der Gaag et al. [47], many of the minorities in different countries tend to land in this category of functional illiteracy. When they seek medical treatment their ability to follow medical instructions are either inadequate or at a marginal literary capacity. A study was conducted in the Netherlands where the findings concluded that their indigenous people were the ones that required significant medical attention [47]. Majority of the studies that were conducted in the 1990s until current conclude that the lack of health literacy abilities are common among the people with the greatest health care needs [27]. This is because they are unable to fully comprehend information (medical prognosis, diagnosis and treatment, insurance policies, medication, etc.); therefore, many people are unsuccessful in their navigation and utilization of the health care system [19] [27] [34].

\section{Health Literacy in Women}

In congruence with functional illiterates, Ford [52] adds that two-thirds of the world's population is made up of illiterate women. Yes, approximately 496 million women are unable to read and comprehend basic information. In another report, the State of the World's Mothers identified adult female literacy rate as one of the 10 key indicators to assess "women's well-being" (Save the Children, 2000). Ford [52] acknowledged that this has been a growing epidemic for over two decades however, the number of illiterate women seems to be growing impetuously. In other studies, there have been high correlations between a mother's level of education and a child's risk of dying before the age of 2 . Some researchers have implies that this is an issue that continues to affect not just the health literacy of adults in this world, but this also affects the literacy of younger individuals. The literacy of a mother plays a significant role in the development of the youth in a community [20], [26].

\section{Health Literacy and Self- Care/Management}

Oliffe et al. [33] found that in terms of medication comprehension approximately $60 \%$ of patients operate at a level that is less than or equal to 
that of an $8^{\text {th }}$ grader. Both studies conducted by Webb et al. [48] and Wolf et al. [51] indicated that multistep instructions were found difficult for patients across all literacy levels. Their yielded results included a controlled group. The inclusion of the controlled groups in each study, allowed researchers to infer that patients who are at low levels of literacy were approximately 3 times less likely to interpret prescription medication warning labels correctly " $95 \%$ confidence interval: 2.3 to 4.9 " [10]. Fortunately, Davis et al. [10] proposed that patients of all literacy levels had a better understanding of warning labels that contained single-step instructions versus multiple-step instructions. In addition, people who have low health literacy are less knowledgeable about their medical conditions and treatment [53]. They receive fewer preventive services [54], report a worsening health status, and are more likely to become hospitalized [3].

In a study by Kim et al. [21] they identified health literacy and self-management behavior in patients with diabetes, their results suggested low literacy was associated with being older. The people that were older in age were found to have; less of an education, lower annual income, and more selfreported diabetes complications [21] [35] also added to the fact that the older people that were studied were unable to answer survey questions correctly. They only were able to answer 2 out of 4 questions accurately [35]. The National Academy on an Aging Society/Center for Health Care Strategies, 1998 reported that poor functional health literacy represents a major cost to the health care industry through inadequate or inappropriate use of medicines [35]. Their illiteracy included missed medical appointments, greater use of health care services including emergency room visits, and poor selfreported health [3].

Due to an individual's lack of information, they are not equipped to make sound medical decisions. Therefore, they utilize the most efficient way of information which is television, radio stations, ads, etc. [40]. This can be both positive and negative because media provides information, however, the information given may not be accurate enough to direct current and future patients effectively [26]. In addition, the Department of Physical Therapy at Northwestern University (2017) surveyed the health literacy knowledge and practices of physical therapists nationwide. They found that only 5\% knew how to administer health literacy assessment tools that test a person's health literacy and only $2 \%$ used established methods to evaluate the reading level of patient education materials (The Department of Physical Therapy at Northwestern University, 2017). This indicates that even some of our health professionals are incapable of teaching their patients how to fully follow treatment plans [12].

\section{Health Literacy and Hospitalization}

In another study, Berkman et al. [6] found that low health literacy was consistently associated with more hospitalizations. They also identified that those who lack healthcare literacy; had greater use of emergency care but they lacked annual examinations and screenings, which are vital to tracking the progress of their conditions. Furthermore, it was identified that the people that lacked health literacy were incapable of demonstrating important procedures required to take medications appropriately [6] [27]. This produced stagnation in treatment and in some cases led to worsening conditions [6]. Adams (2018) illustrates health illiterate individuals also lack the ability to properly interpret labels and important health messages and follow them thoroughly.

\section{Reading Labels}

Webb et al. [48] conducted a study based on literacy and improving medication warning labels. They sampled a total of 86 adult patients who were in a general internal medicine clinic and four adult education classes. In their study the participants underwent face-to-face cognition interviews inclusive of literacy assessment. The assessment was administered to determine the ease of comprehension abilities of the 10 most commonly used drug warning labels [48]. In their findings, 56\% of those that participated in the study were limited in their ability to comprehend the labels given to them. In another study similar to Webb et al. [48], they found that in regard to reading labels, approximately $20 \%$ of the 391 patients observed were reading below the $7^{\text {th }}$ grade level [51]. In both studies, it has been deduced that a patient's ability to comprehend and thoroughly understand the contents of warning labels are associated with their literacy levels [33] [48] [51].

\section{Health Literacy and Oral Language}

It has been found that Eighty percent of the world's populations live in cultures that learn through listening and watching and not through reading and writing [9]. Crain further explains this epidemic as an outcome of work, which places less of an emphasis on reading and writing which are vital priorities in the developing world. One aspect that Crain [9] highlighted was the fact that for women, as work increased their leisure time decreased, therefore, reducing their time to build their literacy. Unfortunately, in developed societies, the focus has pivoted from education to financial success, which has decreased the effectiveness of education and creates plummeting results based on literacy [9] [14]. 
Nouri and Rudd [32] examined the intersection between oral and aural literacy along with the oral exchange. Three tools were developed to measure either patient or provider oral or aural literacy. There was a discrepancy between patient and provider oral and aural literacy levels. It was found that high literacy demand was associated with reduced patient learning and low patient oral or aural literacy was associated with poor health outcomes [16] [32]. Informed patients not only have better outcomes, but they also truly communicate with those who provide health services [15]. The teach-back initiative allows patients the opportunity seek helpful information on the internet, in books, news and places that are newsworthy health studies in context [15] [36].

\section{The Financial Cost of Health Illiteracy}

Howard et al. [19] examined the extent to which low health literacy exacerbates differences between racial and socioeconomic groups. This study was conducted in terms of health status and receipt of vaccinations, sampled 3,260 non-institutionalized elderly persons enrolling in a Medicare managed care plan in 1997 in Cleveland, OH; Houston, TX; South Florida; and Tampa, FL [19]. Participants selfreported their health status, receipt of influenza vaccine, and receipt of pneumococcal vaccine. Independent variables included health literacy, educational attainment, race, income, age, sex, chronic health conditions, and smoking status [19]. The study revealed that individuals without a high school education had worse physical and mental health and worse self-reported health status than those with a high school degree [30]. Gaydosh et al. [13] also agreed with the fact that those who had a higher education had better health status, however, the minorities still had perishing health. Both studies acknowledged that black Americans faced very trying times in their health with post-secondary education. Therefore, literacy affects health status and outcomes however, that is not the case for all ethnicities. Black individuals had worse self-reported health status and lower influenza and pneumococcal vaccination rates [46]. "Health literacy reduced the observed difference in self- reported health by $25 \%$ but did not affect differences in vaccination rates; indicating that health literacy explained a small to a moderate fraction of the differences in health status and, to a lesser degree, receipt of vaccinations that would normally be attributed to educational attainment and/or race of literacy was not considered," [19] [46].

Further studies into health literacy revealed that compared to those with adequate health literacy skills, patients with limited health literacy skills enter the healthcare system when they are experiencing higher levels of sickness [5] [37]. They are also more likely to have chronic conditions and are unable to manage them effectively [42]. Those who are inefficient in health literacy are more likely than persons with adequate health literacy skills to report their health as poor [30]. In a study on the relationship between health care costs and very low literacy skills in a medically needy and indigent Medicaid population, Weiss and Palmer [49] studied persons enrolled in Medicaid because of their medical need/indigence by testing literacy skills in English or Spanish and measuring annual health care charges. Statistical analyses determined if, after manipulating socio-demographic variables, literacy was associated with financial charges [39]. Weiss and Palmer's study [49] yielded that the mean charges among subjects with very low literacy skills ( $\leq 3$ rd-grade reading level) were $\$ 10,688 /$ year, but only $\$ 2,891$ for those with better literacy skills ( $\geq 4$ th-grade reading level), statistically significant difference $(P=.025)$ [49]. This difference persisted after making the necessary changes for potentially confounding sociodemographic variables. This means that very limited reading skills seem to be independently associated with higher health care charges among medically needy and medically indigent Medicaid patients [39].

Another finding by Lal [22] insinuated that there is a cost for illiteracy. Lal "Calculated the cost of illiteracy due to lost earnings and business productivity, missed wealth-creation opportunities, and inadequate high-tech skills capacity at 2 percent of Gross Domestic Product (GDP) for developed countries, 1.2 percent for emerging economies, and 0.5 percent for developing countries - and puts the opportunity cost associated with illiteracy at $\$ 300$ billion for the United States." Health literacy, together with self-management, was listed as one of the 20 priority areas in which quality improvement could transform health care in America [4] Institute of Medicine, 2003). Most studies have also linked self-esteem intrinsically to illiteracy. This malignancy is due to fear, embarrassment, and shame due to the lack of understanding the importance of healthcare [11]. A qualitative study by Brez and Taylor [7] revealed that patients feared that their poor reading skills would be exposed. Patients with low literacy levels would rather sign a document they do not understand than ask questions that will reveal their illiteracy [45]. Patients with low literacy are also more likely to misuse medication as well as forget education on health issues immediately after they leave the appointment office [33].

\section{References}

[1] K. Amadeo, "Why America Is the Only Rich Country Without Universal Health Care", 2019, Retrieved from https://www.thebalance.com/universal-health-care4156211 
[2] D. Anderlini, "The United States HealthCare System is Sick: From Adam Smith to Overspecialization", Cureus, Cureus, Brisbane, Australia, 2018, 1-9. doi:10.7759/cureu s. 2720

[3] S. Badarudeen, and S. Sabharwal, "Assessing Readability of Patient Education Materials: Current Role in Orthopaedics", Clinical Orthopaedics and Related Research, Springer Nature, Los Angeles, CA, USA, 2010, 2572-2580. doi:10.1007/s11999-010-1380-y

[4] I. Bau, R. A. Logan, C. Dezii, B. Rosof, A. Fernandez, M. K. Paasche-Orlow, and W. W. Wong, "PatientCentered, Integrated Health Care Quality Measures Could Improve Health Literacy, Language Access, and Cultural Competence", NAM Perspectives, National Academy of Medicine, Washington D.C., USA, 2019, 1-10. doi: $10.31478 / 201902 \mathrm{a}$

[5] C. L. Bennett, M. R. Ferreira, T. C. Davis, J. Kaplan, M. Weinberger, T. Kuzel,... O. Sartor, "Relation between literacy, race, and stage of presentation among low-income patients with prostate cancer", Journal of Clinical Oncology, American Society of Clinical Oncology, Chicago, IL, USA, 1998, 3101-3104. doi:10.1200/jco.1998.16.9.3101

[6] N. D. Berkman, S. L. Sheridan, K. E. Donahue, D. J. Halpern, and K. Crotty, "Low Health Literacy and Health Outcomes: An Updated Systematic Review", Annals of Internal Medicine, The American College of Physicians, North Carolina, USA, 2011, 97-107. doi: 10.7326/00034819-155-2-201107190-00005

[7] S. M. Brez, and M. Taylor, "Assessing literacy for patient teaching: perspectives of adults with low literacy skills", Journal of Advanced Nursing, John Wiley and Sons, Ontario, Canada, 1997, 1040-1047. doi:10.1046/j.1365-2648.1997.19970251040.x

[8] J. A. Childress, A. Hand, L. Pullins, E. Rutherford, and M. Tye, " The Cyclical Relationship Between Generational Poverty and Poor Education: Breaking the Barrier in Haiti”, The Research and Scholarship Symposium. 2017. http://digitalcommons.cedarville.edu/research_scholarship _symposium/2017/podium_presentations/

[9] C. Crain, "Why We Don't Read, Revisited", 2018. Retrieved from

https://www.newyorker.com/culture/cultural-

comment/why-we-dont-read-revisited.

[10] T. C. Davis, M. S. Wolf, P. F. Bass, M. 3rd, Middlebrooks, E. Kennen, D. W. Baker, ... R. M. Parker, "Low literacy impairs comprehension of prescription drug warning labels", Journal of general internal medicine, Society of General Internal Medicine, Shreveport, LA, 2006, 847-851. doi:10.1111/j.1525-1497.2006.00529.x

[11] P. Easton, V. A. Entwistle, and B. Williams, "How the stigma of low literacy can impair patient-professional spoken interactions and affect health: insights from a qualitative investigation", BMC health services research, BioMed Central Ltd, 2013, 1-12. doi:10.1186/1472-696313-319
[12] G. Elwyn, M. A. Durand, J. Song, J. Aarts, P. J. Barr, Z. Berger, T. V. D. Weijden, "A three-talk model for shared decision making: multistage consultation process", BMJ, BMJ Publishing, 2017, doi:10.1136/bmj .j4891

[13] L. Gaydosh, K. M. Schorpp, E. Chen, G. E. Miller, and K. M. Harris, "College Completion Predicts Lower Depression but Higher Metabolic Syndrome Among Disadvantaged Minorities in Young Adulthood", Proceedings of the National Academy of Sciences, National Academy of Sciences of the United States of America, Chapel Hill, NC, USA, 2017, 109-114. doi: 10.1073/pnas.1714616114

[14] P. Glewwe, and K. Muralidharan, "Improving Education Outcomes in Developing Countries", Handbook of the Economics of Education, Elsevier, 2016, 653-743. doi: 10.1016/b978-0-444-63459-7.00010-5

[15] R. T. Griffey, N. Shin, S. Jones, N. Aginam, M. Gross, Y. Kinsella,... and K. A. Kaphingst, "The impact of teach-back on comprehension of discharge instructions and satisfaction among emergency patients with limited health literacy: A randomized, controlled study", Journal of communication in healthcare, J Commun Healthc., 2015, 10-21. Doi:10.1179/1753807615Y.0000000001

[16] K. F. Harrington, and M. A. Valerio, "A conceptual Model of Verbal Exchange Health Literacy", Patient education and counseling, Elsevier, 2014, 403-410. Doi:10.1016/j.pec.2013.10.024

[17] J. N. Haun, N. R. Patel, D. D. French, R. R. Campbell, D. D. Bradham, and W. A. Lapcevic, "Association Between Health Literacy and Medical Care Costs in an Integrated Healthcare System: A Regional Population Based Study", BMC health services research, BioMed Central Ltd, 2015, 249. Doi: 10.1186/s12913-015-0887-z

[18] L. Hersh, B. Salzman, and D. Snyderman, "Health Literacy in Primary Care Practice", 2015. Retrieved from https://www.aafp.org/afp/2015/0715/p118.html.

[19] D. H. Howard, T. Sentell, and J. A. Gazmararian, "Impact of Health Literacy on Socioeconomic and Racial Differences in Health in an Elderly Population", Journal of General Internal Medicine, Society of General Internal Medicine, Atlanta, GA, USA, 2006, 857-861. doi:10.1111/j.1525-1497.2006.00530.x

[20] J. Katz, A. Parlapiano, and M. Sanger-Katz, "Almost Everywhere, Fewer Children Are Dying”, 2019. Retrieved from

https://www.nytimes.com/interactive/2019/09/17/upshot/c hild-mortality.html.

[21] S. Kim, F. Love, D. A. Quistberg, and J. A. Shea, "Association of Health Literacy with Self-Management Behavior in Patients with Diabetes", Diabetes Care, American Diabetes Association, New Brunswick, NJ, USA, 2004, 2980-2982. doi: 10.2337/diacare.27.12.2980

[22] B. S. Lal, "The Economic and Social Cost of Illiteracy: An Overview", IJARIIE, IJARIIE, Bangalore, India, 2015, 1-8. IJARIIE-ISSN (O)-2395-4396. 1. 
[23] M. Lambert, J. Luke, B. Downey, S. Crengle, M. Kelaher, S. Reid, and J. Smylie, "Health Literacy: Health Professionals' Understandings and Their Perceptions of Barriers that Indigenous Patients Encounter", BMC health services research, BioMed Central Ltd, 2014, 1-10. Doi:10.1186/s12913-014-0614-1

[24] D. Lattier, "32 Million U.S. Adults are "Functionally Illiterate"... What Does That Even Mean?”, 2015. Retrieved from https://www.intellectualtakeout.org/blog/32-million-usadults-are-functionally-illiterate-what-does-even-mean.

[25] J. Ledoux and C. Mann, "Addressing Limitations in Health Literacy", Professional Case Management, Wolters Kluwer Health, Inc., Mount Laurel, NJ, USA, 2019, 219221. doi: $10.1097 / \mathrm{ncm} .0000000000000376$

[26] D. Levin-Zamir, and I. Bertschi, "Media Health Literacy, eHealth Literacy, and the Role of the Social Environment in Context", International Journal of Environmental Research and Public Health, International Journal of Environmental Research and Public Health, 2018, 1-26 . doi:10.3390/ijerph15081643

[27] M. A.-M. Lynch, and G. V. Franklin, "Health Literacy: An Intervention to Improve Health Outcomes", Strategies to Reduce Hospital Mortality in Lower and Middle Income Countries (LMICs) and Resource-Limited Settings, IntechOpen Limited, London, UK, 2019.doi: 10.5772/intechopen.86269

[28] K. McCarthy, "Improving patient health literacy: Strategies for healthcare providers", 2017. Retrieved from https://www.nuemd.com/news/2017/05/29/improvingpatient-health-literacy-strategies-healthcare-providers.

[29] T. A. Miller, "Health Literacy and Adherence to Medical Treatment in Chronic and Acute Illness: A MetaAnalysis", Patient Education and Counseling, Elsevier, Riverside, CA, USA, 2016, 1079-1086. doi:10.1016/j.pec.2016.01.020

[30] A. K. Morrison, A. Glick, and H. S. Yin, "Health Literacy: Implications for Child Health", Pediatrics in Review, American Academy of Pediatrics, 2019, 263-277. doi: 10.1542/pir.2018-0027

[31] R. Murnane, I. Sawhill, and C. Snow, "Literacy Challenges for the Twenty-First Century: Introducing the Issue", The Future of Children, Project Muse, Princeton, NJ, USA, 2012, 3-15. doi: 10.1353/foc.2012.0013

[32] S. S. Nouri, and R. E. Rudd, "Health literacy in the "oral exchange: An Important Element of Patient-Provider Communication”, Patient Education and Counseling, Elsevier, Boston, MA, USA, 2015, 565-571. doi: 10.1016/j.pec.2014.12.002

[33] M. Oliffe, E. Thompson, J. Johnston, D. Freeman, H. Bagga, and P. K. K. Wong, "Assessing the Readability and Patient Comprehension of Rheumatology Medicine Information Sheets: A Cross-Sectional Health Literacy Study", BMJ Open, BMJ Open, New South Wales, Australia, 2019. doi: 10.1136/bmjopen-2018-024582
[34] L. T. Paakkari, M. P. Torppa, O.-P. Paakkari, R. S. Välimaa, K. S. A. Ojala, and J. A. Tynjälä, "Does Health Literacy Explain the Link Between Structural Stratifiers and Adolescent Health?", European Journal of Public Health, Oxford University Press, Jyväskylä, Finland, 2019, 919-924. doi: 10.1093/eurpub/ckz011

[35] N. Parekh, K. Ali, K. Davies, and C. Rajkumar, "Can Supporting Health Literacy Reduce Medication-Related Harm in Older Adults?", Therapeutic Advances in Drug Safety, The Author(s), Brighton, UK, 2018, 167170. https://doi.org/10.1177/2042098618754482

[36] R. M. Parker, S. C. Ratzan, and N. Lurie, "Health Literacy: A Policy Challenge For Advancing High-Quality Health Care", Health Affairs, Project HOPE, Bethesda, Maryland, USA, 2003, 147-153. doi:10.1377/hlthaff.22.4.147

[37] A. M. Panzer, Health Literacy: A Prescription to End Confusion, National Academy of Sciences, Washington, DC, 2004.

[38] I. Poureslami, L. Nimmon, I. Rootman, and M. J. Fitzgerald, "Health Literacy and Chronic Disease Management: Drawing From Expert Knowledge to Set an Agenda", Health Promotion International, Oxford University Press, Vancouver, Canada, 2016, 1-31. doi: 10.1093/heapro/daw003

[39] J. Protheroe, R. Whittle, B. Bartlam, E. V. Estacio, L. Clark, and J. Kurth, "Health Literacy, Associated Lifestyle and Demographic Factors in Adult Population of an English City: a Cross-Sectional Survey", Health Expectations: an International Journal of Public Participation in Health Care and Health Policy, John Wiley and Sons Ltd, UK, 2017, 112-119. doi:10.1111/hex.12440

[40] M. Roberts, L. Callahan, and C. O'Leary, "Social media: A path to health literacy", Information Services and Use, IOS Press, Dortmund, Germany, 2017, 177-187. doi: 10.3233/isu-170836

[41] F. Roncarolo, A. Boivin, J.-L. Denis, R. Hébert, and P. Lehoux, (2017). What do we know about the needs and challenges of health systems? A scoping review of the international literature. BMC Health Services Research, Springer Nature, Danvers, MA, USA, 2017, 118. doi: 10.1186/s12913-017-2585-5

[42] D. Schillinger, J. Piette, K. Grumbach, F. Wang, C. Wilson, C. Daher,... A. B. Bindman, "Physician Communication With Diabetic Patients Who Have Low Health Literacy", Archives of Internal Medicine, JAMA Network, and San Francisco-90. 2003, doi: 10.1001/archinte.163.1.83

[43] L. Shi, and D. A. Singh, U. S. Health Care System, Jones and Bartlett Learning, Burlington, MA, 2017. [44] K. Sørensen, S. Van den Broucke, J. Fullam, G. Doyle, J. Pelikan, Z. Slonska, H. Brand, "Consortium Health Literacy Project European, Health Literacy and Public Health: A Systematic Review and Integration of Definitions and Models", BMC public health, Springer 
Nature, Danvers, MA, USA, 2012, 1-13. doi:10.1186/1471-2458-12-80

[45] H. Storms, N. Claes, B. Aertgeerts, and S. Van den Broucke, "Measuring Health Literacy Among Low Literate People: An Exploratory Feasibility Study with the HLS-EU Questionnaire", BMC public health, Springer Nature, Danvers, MA, USA, 2017, 1-10. doi:10.1186/s 12889-017-4391-8

[46] S.C Tse, L. C. Wyatt, C. Trinh-Shevrin, and S. C. Kwon, "Racial/Ethnic Differences in Influenza and Pneumococcal Vaccination Rates Among Older Adults in New York City and Los Angeles and Orange Counties", Preventing Chronic Disease, Centers for Disease Control and Prevention, 2018, 1-2. doi:10.5888 /pcd15.180101

[47] M. van der Gaag, I. van der Heide, P. Spreeuwenberg, A. Brabers, and J. Rademakers, "Health Literacy and Primary Health Care Use of Ethnic Minorities in the Netherlands", BMC Health Services Research, Springer Nature, Netherlands, 2017, 1-9. doi:10.1186/s12913-0172276-2

[48] J. Webb, T. C. Davis, P. Bernadella, M. Clayman, R. M. Parker, D. Adler, and M. S. Wolf, "Patient-Centered Approach for Improving Prescription Drug Warning Labels", Patient Education and Counseling, Elsevier, Ireland, 2008, 443-449. doi: 10.1016/j.pec.2008.05.019

[49] B. D. Weiss, and R. Palmer, "Relationship Between Health Care Costs and Very Low Literacy Skills in a Medically Needy and Indigent Medicaid Population", The Journal of the American Board of Family Medicine, The Journal of the American Board of Family Medicine, Tucson, AZ, USA, 2004, 44-47. doi:10.3122/jabfm .17 .1 .44

[50] WHO. (2010). Track 2: Health literacy and health behaviour. https://www.who.int/healthpromotion/conferen ces/7gchp/track2/en/. (Access date: 1 November, 2016).

[51] M. S. Wolf, T. C. Davis, L. M. Curtis, J. A. Webb, S. C. Bailey, W. H. Shrank, ... A. J. Wood, "Effect of Standardized, Patient-Centered Label Instructions to Improve Comprehension of Prescription Drug Use", Medical care, Wolters Kluwer Health, Inc., Chicago, IL, USA, 2011, 96-100. doi:10.1097/MLR.0b013e3181f381 74.

[52] Ford, L., (2015). Two-thirds of world's illiterate adults are women, report finds. The Guardian. https://www.theguardian.com/global-development/2015/oc t/20/two-thirds-of-worlds-illiterate-adults-are-women-repo rt-finds. (Access date: 1 November, 2017).

[53] Williams, M.V., Baker, D.W., Parker, R.M., Nurss, J.R., (1998). Relationship of Functional Health Literacy to Patients' Knowledge of Their Chronic Disease. Arch Intern Med. Vol 158.

[54] Scott, T. L., Gazmararian, J.A., Williams, M. V., Baker, D.W., Health Literacy and Preventive Health Care Use Among Medicare Enrollees in a Managed Care
Organization, Medical Care: May 2002 - Volume 40 Issue 5 - p 395-404. 